RESEÑAS

\title{
CAHUC Pierre, ZYLBERBERG André. 2016. Le Négationnisme économique et comment s'en débarrasser ?, Paris: Flammarion, 240 p.
}

CAHUC Pierre, ZYLBERBERG André. 2016. La negación económica y la manera de deshacerse. Paris: Flammarion, 240 p.

\section{Benoît Mougenot}

Universidad San Ignacio de Loyola, Lima, Perú.

\author{
Recibido 10-05-17 \\ Aprobado 05-07-17 \\ En Línea 08-08-17
}

Correspondencia

Email: bmougenot@usil.edu.pe

Citar como:

Mougenot, B. (2017). CAHUC Pierre,
ZYLBERBERG André. 2016. Le Négationnisme
économique et comment s'en débarrasser?, Paris:
Flammarion, 240 p. Propósitos y Representaciones,
5(2), 483 - 490.. doi: http://dx.doi.org/10.20511/
pyr2017.v5n2.160

(C) Universidad San Ignacio de Loyola, Vicerrectorado de Investigación, 2017.

(cc) BY-NC-ND Este artículo se distribuye bajo licencia CC BY-NC-ND 4.0 Internacional (http://creativecommons.org/licenses/by-nc-nd/4.0/). 
El libro de los autores Pierre Cahuc et André Zylberberg presenta el tema de la verdad científica en el espacio público, frente a la presencia de grupos de interés o personas que se identifican como expertos (académicos, políticos o representantes de interés privados) y que influyen en la toma de decisión de las políticas públicas. El argumento principal del libro expone la importancia de desarrollar una verdad científica basada en la generación de evidencia, con el uso de un método experimental. Asimismo, el libro presenta una serie de ejemplos de casos empíricos, que movilizan una experimentación natural, en diferentes temas como las políticas energéticas, educativas, o fiscal, entre otros.

En los últimos tiempos una serie de evolución muy importante ha revolucionado la investigación, particularmente en economía, que le permite ahora ser considerada por los autores como una ciencia exacta, como la medicina o la biología. El desarrollo de la informática moderna ha permitido la creación y la gestión de bases de datos considerables, en paralelo al desarrollo de técnicas de tratamiento de la información altamente sofisticadas. Los autores ponen la luz en el desarrollo de una metodología basada en el desarrollo de protocolo de experimentación. El uso de este método en economía facilita la obtención de resultados por la comparabilidad entre grupos. Generalmente, se compara un "grupo test" donde se establece la reforma o el programa de políticas públicas y el otro grupo de control, sin el efecto (p.14). Según ellos, este método de investigación basado en la medicina transforma la economía en una ciencia experimental, no por su objeto de estudio sino por su método.

El uso de un método de trabajo científico se refleja a través la difusión de los resultados al nivel internacional que permiten asegurar de su calidad, como la publicación de artículos en las revistas académicas revisadas por pares y de alto impacto.

Si esta perspectiva se ha generalizada, no está reconocida por todos los académicos. El debate en Francia tiene raíces profundas, el libro resalta la larga tradición crítica contra la ciencia y la economía de influencia liberal, 
ilustradas por autores emblemáticos como Pierre Bourdieu o Jean-Paul Sartre que critican su representación como herramienta de dominación. Según los autores, los académicos heterodoxos perpetúan esta tradición crítica contra la globalización o la finanza internacional, sin sustentos empíricos robustos. Son los representantes de colectivos que promueven una cierta forma de pluralidad de los aportes metodológicos de la economía, como la revista Alternatives Economiques o la Asociación Francesa de Economía Publica (AFEP). Asimismo, esta asociación promueve el desarrollo de una nueva sección reconocida por el Consejo Nacional Universitario (CNU) que permitiría la contratación de profesores universitarios de economía considerados como heterodoxos y en relación con otras disciplinas, como la historia. Los autores critican la influencia de este grupo y su contribución regular en los medios de comunicación. Además, la crítica supera el estricto ámbito académico para ser dirigida contra los representantes de interés económicos que se reclaman expertos y que según los autores prefieren ocultar la evidencia empírica para garantizar sus intereses, como la industria del cigarro contra el cáncer de los fumadores a partir de los años cincuenta, o la industria del petróleo sobre la existencia del cambio climático.

Los dos autores del libro son profesores de economía reconocidos con especialización en el mercado laboral (Universidad Paris-1 PanthéonSorbonne) y representan un grupo intelectualmente cercano de personas como Jean Tirole (titular del Premio Nobel de Economía). La publicación del libro en septiembre 2016 ha revelado un debate intenso e interesante en Francia entre varios representantes de la disciplina económica. Asimismo, el uso de la metodología experimental no se generaliza todavía a todo el campo de la investigación en economía. En realidad, estos tipos de experimentación son difíciles a desarrollar y sometidas a errores por límites de los datos. Se revelan pertinentes en el caso de muestras reducidas y en un perímetro bien delimitado para limitar los sesgos, la economía del desarrollo tiene varios ejemplos ilustrados en el libro. En macroeconomía, la comparación del efecto de una misma reforma como el aumento del salario minio para reducir 
el desempleo entre dos países se revela más difícil, porque cada uno tiene su propia particularidad.

Las palabras usadas en el libro revelan una voluntad bastante crítica y antagonista contra la posición de los autores considerados como heterodoxos. Se ilustra a través la reivindicación del uso del término negacionismo (négationnisme en francés) en el título y la descripción de un paralelo entre un negacionismo científico, es decir que niega le evidencia basada en el uso de una metodología científica y un negocianismo históricamente representados por los nazis sobre la existencia del holocausto durante la segunda guerra mundial. Asimismo, si el debate es necesario el uso de palabras con una dimensión simbólica extremamente fuerte no contribuye a dar una visión clara de los distintos argumentos.

La presencia de varias escuelas de pensamiento ha sido siempre una característica importante de la economía (marxista, keynesiana, neoclásica, entre otros), la disminución de esta diversidad y su influencia en la publicación de artículos en las revistas académicas ha sido ineluctable en los últimos años. Sin embargo, la presencia del retorno de un debate intenso entre economistas en el espacio público implica la necesidad de relativizar ese argumento de dominación positivista.

\section{Referencias}

Cahuc, P., \& Zylberberg, A. (2016). Le Négationnisme économique et comment s'en débarrasser?. Paris: Flammarion. 